\title{
ZONEAMENTO TÉRMICO E SUAS CORRELAÇÕES ASSOCIADAS AOS PADRÕES DE USO E OCUPAÇÃO DA TERRA DA REGIÃO URBANA, CENTRO EM JUIZ DE FORA - MG
}

\author{
ASSIS, Débora Couto - cassis.debora@gmail.com \\ Universidade Federal de Juiz de Fora / UFJF
}

FERREIRA, Cassia Castro Martins - cassia.castro@ufjf.edu.br

Universidade Federal de Juiz de Fora / UFJF

\begin{abstract}
RESUMO: A atual dinâmica de urbanização resulta no avanço de ambientes antropizados sobre o meio natural, gerando um clima essencialmente urbano, o qual pode originar desequilíbrios prejudiciais à saúde da população. Assim existe a necessidade de estudos que avaliem as condições deste ambiente modificado, diante deste contexto, o presente trabalho tem como objetivo identificar padrões e processos relacionados ao uso-ocupação da terra e as relações estabelecidas com os elementos climáticos, enquanto contribuição para formação de zonas de conforto térmico na região central de Juiz de Fora - MG. O trabalho foi realizado através do tratamento dos dados secundários e coletados em campo, com a utilização de ferramentas de geoprocessamento. Como resultado constatou-se diferentes zonas de conforto térmicos dentro da região urbana do centro, algumas delas se apresentam desconfortáveis à população, devido aos baixos índices de temperatura efetiva verificados, ou seja, sensação de frio, revelando a função da vegetação e os corpos hídricos na diminuição das temperaturas.
\end{abstract}

PALAVRAS-CHAVES: Conforto Térmico; Clima Urbano; Uso e Ocupação da Terra

THERMAL ZONE AND THEIR CORRELATIONS ASSOCIATED WITH THE PATTERNS OF USE AND OCCUPATION OF THE LAND IN THE URBAN REGION, CENTER IN JUIZ DE FORA - MG

ABSTRACT: The current dynamics of urbanization results in the advance of anthropized environments over the natural environment, creating an urban final climate, that may lead to imbalances that are detrimental to the health of the population. Thus, there is a need for studies that evaluate the conditions of this modified environment, in this context, the present work aims to identify patterns and processes related to land use and occupation and relationships established with climatic elements, as contribution to the formation of zones of thermal comfort in the central region of Juiz de Fora - MG. This work was done through the handling of the secondary data and collected in the field, with the use of geoprocessing tools. As a result, different zones of thermal comfort were found within the urban area of the center, some of them are uncomfortable to the population, due to the low effective temperature indices verified, in the other words, cold sensation, showing the function of vegetation and water bodies in decreasing temperatures.

KEYWORDS: Thermal comfort; urban climate; land use and occupation.

\section{INTRODUÇÃO}

A partir da segunda metade do século $X X$, o Brasil vivenciou uma acelerada transição urbana por meio do processo de industrialização, o que culminou no aumento da proporção da população em relação ao espaço físico urbano. Para comportar este grande contingente de pessoas, as cidades foram tomando maiores dimensões, muitas vezes sem qualquer tipo de planejamento prévio.

O Brasil, incluído na condição de em desenvolvimento, apresenta uma dinâmica de urbanização que resulta na segregação social e espacial e na exclusão de grande parte de sua população (SANTOS, 1994). Atualmente, cerca 
de $85 \%$ da população brasileira habita áreas urbanas (IBGE, 2010) as quais, em sua maioria, crescem desordenadamente.

O alto índice de urbanização brasileiro ocasiona problemas de difícil administração e correção, sem que sejam destinados recursos para investimentos essenciais, além de uma maior vulnerabilidade da população mais desfavorecida ao desconforto. Essa parcela da sociedade geralmente é induzida a se estabelecer nos espaços mais degradados da cidade, onde é possível que as condições climáticas específicas agravem ainda mais os baixos índices de qualidade de vida.

Oke $(1973,1981,1999)$ demonstrou que o clima da cidade é produto de um fenômeno de transformação de energia a partir da interação entre o ar atmosférico e o ambiente urbano construído. Este enfatiza a diferença entre os processos térmicos rural e urbano e coloca em evidência a geometria urbana e a inércia térmica dos materiais de construção no processo de mudança climática causados pelos assentamentos urbanos. Segundo Monteiro "o clima urbano pode ser definido como um sistema que abrange o clima de um dado espaço terrestre e sua urbanização" (MONTEIRO, 1976, p. 95). E, portanto, tanto os fatores de origem antrópica, quanto os naturais, devem ser analisados, a fim de se chegar a uma análise completa da dinâmica climática urbana. Os elementos constituintes do urbano criam um campo térmico específico e formam microclimas diferenciados que por sua vez, podem reduzir a qualidade de vida dos citadinos.

As formas urbanas redesenham o meio, como pode ser visualizado na densidade e geometria das verticalizações que tornam a superfície cada vez mais rugosa influenciando na circulação do ar, no transporte de calor e vapor d'água e na existência de áreas sombreadas devido às barreiras formadas pelas edificações. Os diversos tipos de materiais que constituem essa arquitetura urbana, como materiais de construção e asfaltamento, retém mais calor e impermeabilizam solo.

Neste contexto destaca-se a importância da vegetação na determinação de um clima urbano mais ameno, a ausência de vegetação atrelada a esta alteração da paisagem natural traz consigo mudanças no clima local, e por consequência revela diferentes sensações térmicas, que podem prejudicar o conforto térmico da população citadina. Podemos entender, portanto, que uma das funções mais importantes da cobertura vegetal é o sombreamento. O sombreamento tem a finalidade de amenizar o rigor térmico da estação quente no clima subtropical e durante o ano na região tropical (MASCARÓ, 1990), auxilia na redução da temperatura máxima do ar e da amplitude térmica durante o dia, através da troca constante de calor sensível com o ar do sítio urbano.

O conforto térmico consiste no conjunto de elementos que permitem que mecanismos de autorregulação sejam mínimos, ou ainda que a zona delimitada por características térmicas em que o maior número de pessoas manifeste-se sentir bem (GARCIA, 1985). Considerado o canal termodinâmico do clima urbano, o conforto térmico tem como fonte a atmosfera e a radiação, possui um desenvolvimento contínuo, tem como principais produtos a formação de ilhas de calor e problemas de ventilação. Para evitar ou até mesmo corrigir problemas urbanos em relação ao conforto térmico deve-se tomar medidas de controle do uso da terra. 
Segundo Souza \& Nery (2013) o laboratório de Meteorologia Aplicada a Sistemas de Tempo Regionais (MASTER - IAG/USP), utiliza o índice de temperatura efetiva em função do vento para prever as condições de conforto térmico no Sul, Sudeste e Centro-Oeste do Brasil. Sendo que o laboratório MASTER considera como termicamente confortável o intervalo entre $22,0^{\circ} \mathrm{C}$ e $25,0^{\circ} \mathrm{C}$. Temperaturas inferiores a $22^{\circ} \mathrm{C}$ correspondem a sensações que variam de ligeiramente fresco a muito frio e acima de $25,0^{\circ} \mathrm{C}$ considera-se de ligeiramente quente a muito quente (SOUZA; NERY, 2013).

Gobo (2013) avaliou o conforto térmico para o Rio Grande do Sul de acordo com o Índice de temperatura efetiva em função do vento, segundo as médias mensais e sazonais, com a finalidade de estabelecer uma regionalização climática para o estado com base no zoneamento de conforto térmico.

Neste sentido, a informática, vem propiciando um refinado conjunto de instrumentos voltados ao mapeamento, análises e representações de dados e informações relacionadas ao meio ambiente. Desta forma, o geoprocessamento, mais especificamente para este trabalho, os sistemas de informações geográficas (SIG) aparece como um instrumento voltado ao mapeamento, monitoramento, avaliação e quantificação das áreas verdes da cidade e suas relações com as diferentes formas de ocupação e organização da população urbana.

Aliado à demanda de melhor conhecer e individualizar as zonas de conforto térmico no sítio urbano da região central da cidade de Juiz de Fora, constata-se a crescente necessidade de obtenção de dados sobre a dinâmica espacial na área urbana da cidade, atrelada, sobretudo ao desenvolvimento de métodos capazes não só de mapear, mas também de analisar padrões espaciais geradores das zonas de conforto destacadas, para assim avaliar a importância de processos envolvidos. Sendo assim o presente trabalho tem o objetivo identificar padrões e processos relacionados ao uso da terra, à vegetação, aos fatores climáticos e ao crescimento e adensamento urbano, enquanto contribuição para a sensação térmica, bem como para o fornecimento de subsídios ao planejamento urbano/ambiental na região central de Juiz de Fora MG.

\section{CARACTERIZAÇÃo DA ÁREA DE ESTUDO}

\subsection{O MUNICÍPIO DE JUIZ DE FORA}

O município de Juiz de Fora está localizado na Zona da Mata do estado de Minas Gerais, mais precisamente nas coordenadas geográficas $21^{\circ} 45^{\prime} 50^{\prime \prime} \mathrm{S}$ e $43^{\circ} 21^{\prime} 00^{\prime \prime}$ W, o qual pode ser observado no Figura 1- Mapa de localização do Município de Juiz de Fora- MG. O município possui uma área de 1.435,66 km2 e uma população de 517.872 habitantes (IBGE, Censo Demográfico, 2010).

Segundo Torres (2006, p. 162) "o clima de Juiz de Fora apresenta duas estações bem definidas: uma que vai de outubro a abril, com temperaturas mais elevadas e maiores precipitações pluviométricas, e outra de maio a setembro, mais fria e com menor presença de chuvas". A época das chuvas concentra $83,9 \%$ das precipitações, enquanto a estação seca, 16,1\%. 


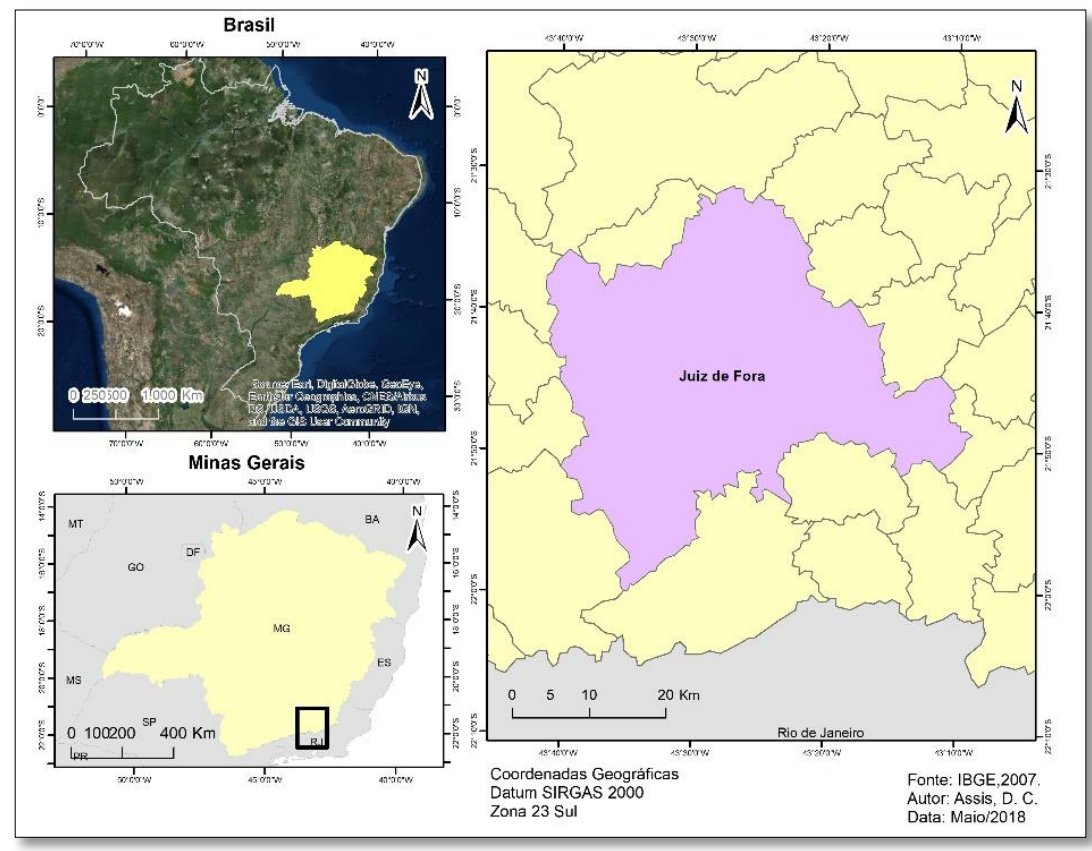

Figura 1- Mapa de localização do Município de Juiz de Fora- MG.

\section{2 - REGIÃO CENTRAL}

O perímetro urbano de Juiz de Fora, foi subdividido pela prefeitura em 81 regiões urbanas, que podem ser observadas no encarte da Figura 2. A partir dessa subdivisão pode-se encontrar a região central de cidade, a qual se enquadra dentro da Região urbana 55, denominada Centro. Possui uma área de 0,75 km2 e uma população residente de mais de 20 mil habitantes (IBGE,2010), porém devido a função que este exerce na organização interna da cidade o fluxo de pessoas na área central é intenso. Segundo Tasca (2010) em termos urbanísticos, nas décadas de 80 e 90 houve um processo de verticalização do Centro e de seu entorno, em contraposição a um crescimento horizontalizado na periferia. O centro detém unidades de uso comercial, além de possuir escolas, equipamentos de saúde e todo o setor administrativo da cidade. 


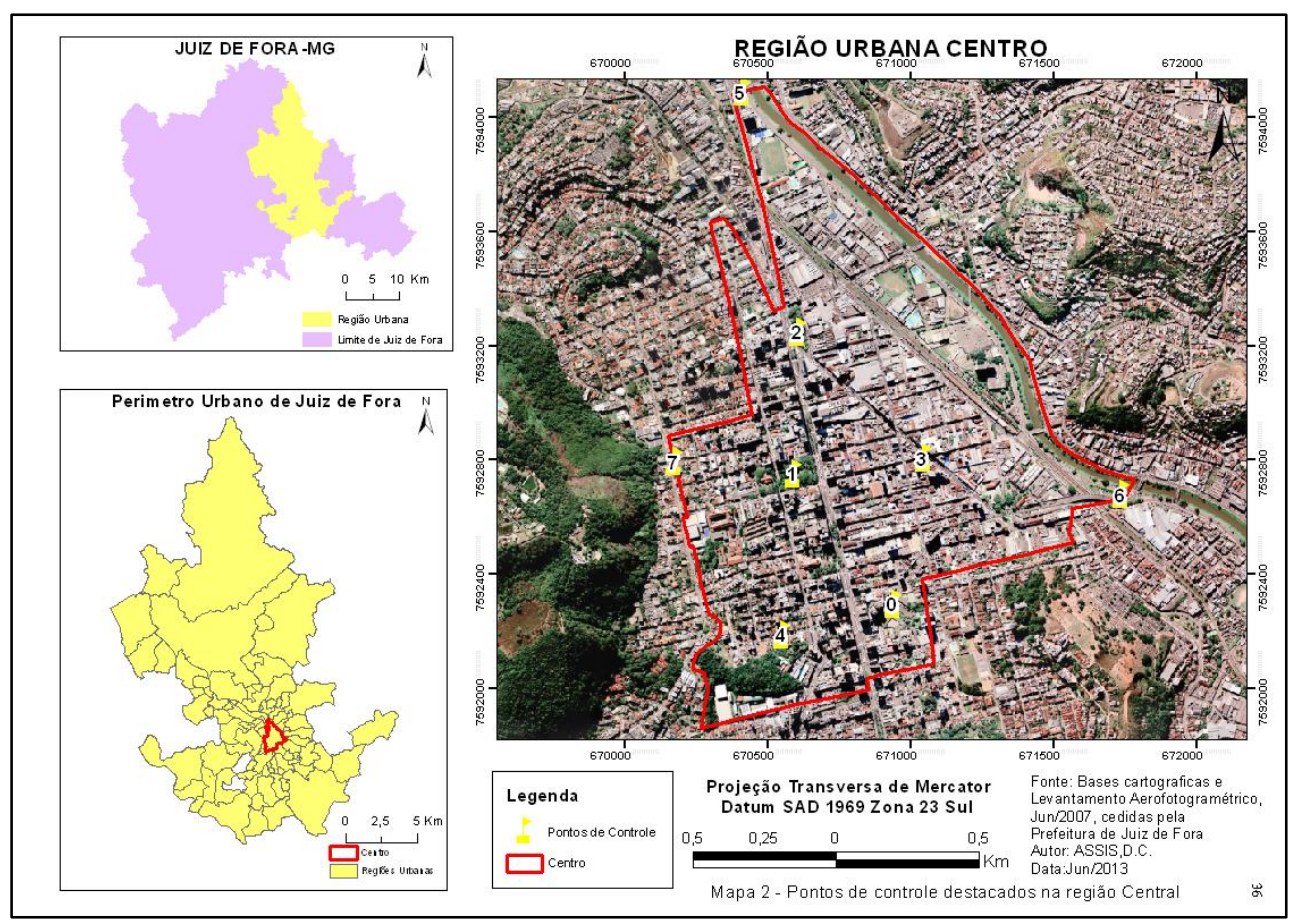

Figura 2 - Mapa da Região Central

\section{3 - OS PONTOS DE CONTROLE ITINERANTES}

Os pontos de controle são os locais onde as estações meteorológicas foram alocadas para realização das medições, estes podem ser visualizados nas Figuras 2 e 3, sendo o primeiro ponto de controle o Parque Halfeld, que para 0 acervo histórico da prefeitura municipal, é reconhecido como antigo Jardim Municipal. O local era escolhido para instalação das diversões itinerantes que passavam pela cidade, uma vez que Juiz de Fora não possuía nenhuma forma regular de entretenimento. O Parque Halfeld constitui-se, desde a sua criação, em um dos mais importantes símbolos de Juiz de Fora. Situado entre as suas principais ruas - Halfeld, Santo Antônio e Av. Barão do Rio Branco, com cerca de 12 mil metros quadrados como presença de vegetação expressiva.

Embora denominado como Parque, este não se enquadra neste conceito, pois segundo Lima (1994) parque urbano é uma área verde, com função ecológica, estética e de lazer, no entanto com uma extensão maior que as praças e jardins públicos, e praças sendo um espaço livre público, cuja principal função é o lazer, sendo mais adequado, portanto, considerá-lo como uma praça.

O ponto número 2, a Praça do Largo de Riachuelo, localiza-se entre as avenidas Getúlio Vargas e Barão do Rio Branco, atualmente possui cerca de 5 mil metros quadrados com presença de vegetação arbórea significativa diante da realidade da Região Central.

O ponto 3, localizado na antes conhecida como Rua Califórnia, a Rua Halfeld caracteriza-se por se situar em um local completamente impermeabilizado, edificado e com grande fluxo de pessoas e veículos automotores, sendo que no trecho entre a Av. Rio Branco e Av. Getúlio Vargas 
encontra-se o calçadão, no qual não é permitido o tráfego de veículos, sendo transitado apenas por pedestres. Este ponto de controle foi alocado mais precisamente no cruzamento entre o calçadão da Rua Halfeld e a Av. Getúlio Vargas. Além de este cruzamento encontrar-se cercado por inúmeras edificações, gerando diversas áreas de sombreamento em alguns momentos do dia, possui um fluxo intenso de veículos, pelo fato de tratar de uma das principais vias de circulação do centro da cidade.

O ponto de controle 4, foi fixado na rua Rei Alberto em frente a casa de número 243, caracteriza-se pela grande presença de edificações, destacando-se por um menor fluxo de veículos e pedestres em relação a outros pontos, além de existir muito próximo ao ponto um fragmento de vegetação.

O ponto 5 encontra-se na Av. Brasil, número 4150 na base de Juiz de Fora da Policia Federal. Neste ponto, as medições foram realizadas através de uma estação automática, a qual ficou desativada por alguns meses para manutenção e retornou as atividades no dia 23 de Julho de 2013, este ponto caracteriza-se por edificações não muito elevadas em sua maioria, porém ainda sim existem imóveis deste tipo de uso, outra característica importante a ser destaca é a proximidade do rio Paraibuna o qual é, efetivamente, considerado o maior afluente em volume de água do rio Paraíba do Sul.

O ponto 6, se encontra no extremo sudeste da área de estudo, entre a Av. Brasil e a Rua Espírito Santo, a apenas alguns metros da calha do Rio Paraibuna a margem direita do rio, possuindo alguns exemplares de vegetação arbórea. Porém também existe uma grande circulação de veículos, até mesmo de veículos pesados. A área que circunda o ponto, considerando apenas a margem direita do rio, não possui muitas residências, nem mesmo unidades de natureza comercial ou serviços, além da indústria Gráfica Esdeva e a sede do jornal Tribuna de Minas.

Enfim, o ponto de controle 7 é de maior altimetria da área de estudo, possuindo 740 metros de altitude, localiza-se no cruzamento entre a rua Constantino Paleta e Olegário Maciel, tem a natureza das unidades dos imóveis divididas entre apartamentos, casas e lojas, assim existe um fluxo de veículos considerável, principalmente na rua Olegário Maciel, pois a mesma corta vários bairros ligando o centro a zona oeste da cidade. 

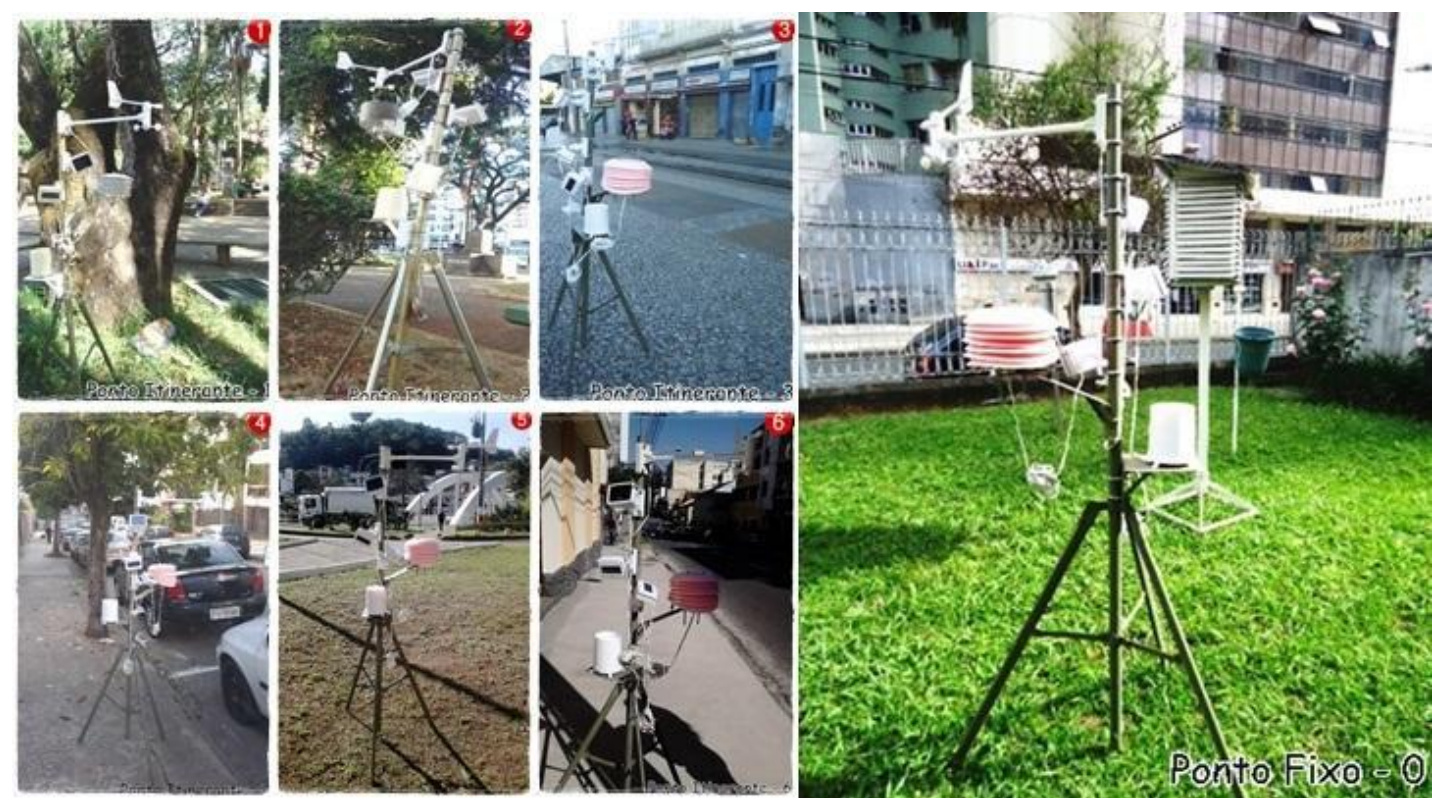

Figura 3 - Fotos das estações em campo. Fonte: Assis, D.C.

\subsection{PONTO FIXO - COLÉGIO STELLA MATUTINA}

O ponto de controle fixo é onde ficou alocada a estação meteorológica durante todos os dias de medições e este foi estabelecido no Colégio Stella Matutina, localizado na Avenida Itamar Franco, o qual possui uma parceria com o Laboratório de Climatologia e Análise ambiental (LabCAA) da UFJF. Além desta parceria, o motivo pelo qual o ponto foi escolhido é devido às condições dos seus arredores, pois este ponto se localiza em uma das principais vias do centro de Juiz de Fora possuindo, portanto, um significativo fluxo de veículos automotores durante todo o dia, principalmente nos horários picos de circulação da população, além de ser circundado por edifícios com muitos pavimentos.

\section{MATERIAS E MÉTODOS}

O trabalho pretende apresentar os impactos do crescimento urbano na região central da cidade de Juiz de Fora através da perspectiva do conforto térmico, com ênfase no canal de percepção termal, utilizando dados meteorológicos primários coletados diretamente em campo, dados estruturais secundários cedidos pela Prefeitura de Juiz de Fora (Departamento de cadastro imobiliário), além de levantamentos de bibliografia, confecção de gráficos climatológicos e mapas temáticos.

A metodologia pode ser separada em três etapas, a primeira consistiu na consolidação de um referencial teórico, através de uma revisão bibliográfica. Além da organização dos trabalhos de medição no campo, em que foram escolhidas as localidades a serem alocados os pontos de controle.

Entende-se como ponto de controle o local onde foi alocada a estação meteorológica para realização das medições em campo. Para escolha destes pontos foram adotados critérios como a seleção de áreas com maior 
verticalização, impermeabilização, intenso fluxo de veículos automotores, praças com presença de vegetação arbórea significativa, além da segurança do equipamento.

Para realização dos trabalhos de campo, o trabalho contou com apoio dos bolsistas e equipamentos cedidos pelo Laboratório de Climatologia e Análise Ambiental (LabCAA), da Universidade Federal de Juiz de Fora.

A segunda etapa constituiu na realização dos trabalhos de campo, nos quais foram utilizadas duas estações meteorológicas portáteis modelo WNR928NX da marca Óregon. Desse modo foram realizadas medições das variáveis de temperatura, umidade relativa do ar e velocidade do vento em oito pontos distintos, sendo um ponto fixo, o Ponto 0 - localizado no colégio Stella Matutina, sendo feito neste a medição todos os dias do campo, já os demais foram pontos foram itinerantes, ou seja, a cada dia foi feita a medição em um local.

As medições foram realizadas durante 9 horas e meia nos dias 18, 19,20 e 21 de Junho, 30 de Julho e 01 de Agosto, sendo iniciadas às 8 horas da manhã e encerradas às 17 horas e trinta minutos de cada dia, o intervalo adotado entre as medições foi de 15 minutos, ou seja, de 15 em 15 minutos eram registrados os valores das variáveis.

Ainda nesta etapa foram realizadas análises sinóticas com objetivo de relacionar os dados em campo com a atuação dos fatores de macro escala, através das cartas sinóticas de altitude e superfície disponibilizadas pelo Centro de Previsão de Tempo e Clima (CPTEC/INPE), nos dias de coletas de dados, de maneira a visualizar os sistemas atmosféricos atuantes no período.

A terceira etapa dividiu-se em quatro partes, sendo que a primeira se iniciou com a tabulação dos dados coletados em campo. Posteriormente aplicação do de temperatura efetiva (TEv). Foi feito o cálculo da temperatura efetiva, para o período da manhã e da tarde. Para isto foram calculadas as médias para dois momentos do dia, para a manhã, que consistiu o período de 8 horas as 12 horas e 30 minutos e para a tarde, no intervalo de 12 horas e 45 minutos as 17 horas e 30 minutos. O cálculo do índice de temperatura efetiva foi realizado para cada dia de medição. O Índice de temperatura efetiva pode ser encontrado em Suping et al. (1992) e o Critério de Fanger (1972), que através de uma fórmula, analisa-se temperatura do bulbo seco, umidade relativa e velocidade do vento, este também é um índice útil para os trópicos, que pode ser obtido através da fórmula de Suping et al. (1992):

\section{Índice de temperatura efetiva:}

$$
T E v=\frac{37-(37-T)}{\left[0.68-0,0014 \times U R+\frac{1}{\left(1,76+1,4 \times v^{0,75)}\right)}\right]}-0,29 \times T\left(1-\frac{U R}{100}\right)
$$

Onde:

$T E v$ é temperatura efetiva como função do vento, temperatura do ar e umidade relativa $\left({ }^{\circ} \mathrm{C}\right)$;

T é a temperatura do bulbo seco $\left({ }^{\circ} \mathrm{C}\right)$; 
UR é a umidade relativa (\%) e

v é a velocidade do vento $(\mathrm{m} / \mathrm{s})$.

Estabelecendo uma temperatura 'confortável' para o ser humano entre $22^{\circ} \mathrm{C}$ à $25^{\circ} \mathrm{C}$. Com o resultado adquirido através da fórmula é possível classificar a zona de conforto encontrado através das classes estabelecidas por (FANGER, 1972)

Tabela 1 - Zonas de conforto térmico e respectivas respostas fisiológicas.

\begin{tabular}{cll}
\hline TEv ( $\left.{ }^{\circ} \mathbf{C}\right)$ & $\begin{array}{l}\text { Sensação Térmica } \\
\text { (Tipo de Tempo) }\end{array}$ & Grau de estresse fisiológico \\
\hline$<13$ & Muito Frio & Estremo estresse ao frio \\
$13-16$ & Frio & Tiritar/Tremer \\
$16-19$ & Frio Moderado & Ligeiro resfriamento do corpo \\
$19-22$ & Ligeiramente Frio & Vasoconstrição \\
$22-25$ & Confortável & Neutralidade térmica \\
$25-28$ & Ligeiramente quente & Ligeiro suor, vasodilatação. \\
$28-31$ & Quente Moderado & Suando \\
$31-34$ & Quente & Suor em Profusão \\
$>34$ & Muito quente & Falha na termorregulação
\end{tabular}

Fonte: (FANGER, 1972 adaptadas por MAIA e GONÇALVES,2002)

Finalizado esta etapa fez-se a aquisição e tratamento dos dados do meio físico e socioeconômico, mapeando os padrões mutáveis de uso e cobertura da terra, que consistem nas características que podem ser modificadas com decorrer do tempo, como vegetação, cursos d'água e albedo. Para tanto, utilizou-se dados cedidos pela Prefeitura de Juiz de Fora, sendo estes dados: camada de lotes, logradouros, curvas de nível, hidrografia, delimitação das regiões urbanas, além das tabelas com as informações das características da unidade presente dentro de cada lote e a imagem do levantamento aerofotogramétrico de 2007, englobando a Região Central. Foi estabelecido como datum padrão SAD 1969, zona 23 Sul, pelo fato de ser datum padrão adotado pela Prefeitura, não sendo necessário reprojetar as bases.

Com o uso de um Sistema de Informações Geográficas (SIG), foram espacializadas e mapeadas cada uma das variáveis, como vegetação, curso d'água, delimitação dos lotes, tipologia, pavimentos e natureza da unidade e albedo. E a partir dos dados coletados através das medições em campo foram mapeadas as zonas termais, além das zonas de sensação térmica. 
Logo, a partir dados dos coletados foram elaborados o material cartográfico, através das técnicas de Geoprocessamento utilizando o software ArcGis 10, sendo gerados os seguintes mapas:

1. Localização do Município de Juiz de Fora - MG.

2. Pontos de controle destacados na região Central.

3. Hipsometria da Região Central.

4. Temperatura na Região Central.

5. Albedo da Região Central.

6. Vegetação e Hidrografia da Região Central.

7. Edificações da Região Central.

8. Sensação Térmica na Região Central (Manhã e Tarde).

Para elaboração dos mapas 1 e 2 foram adicionados no ambiente Arcmap as camadas de limites territoriais do país Brasil, estado de Minas Gerais, município de Juiz de Fora e o shapefile dos pontos de controle criado no ambiente ArcCatalog, posteriormente, fez-se o georreferenciamento dos pontos de controle na área de estudo, utilizando a ferramenta de edição vetorial.

Para criação dos mapas de Hipsometria e Vegetação o procedimento foi o mesmo, adicioná-los no ambiente Arcmap a única diferença é que neste foi criado um shapefile de vegetação e a mesma vetorizada em polígonos através das imagens Aerofotogramétricas de 2007 de escala 1:2000, estabelecendo o Datum padrão, gerando separadamente cada mapa.

Já os mapas de Edificações e Albedo foram gerados através da camada de lotes e tabelas com informações da unidade, para isto o shapefile e as tabelas foram adicionadas no ambiente Arcmap, e dentro do mesmo foi realizado joins entre a camada e as tabelas buscando ligar a informação da unidade a cada lote, permitindo verificar quantos pavimentos possuem o imóvel localizado em cada lote, destacando que no levantamento da prefeitura não se considera os pavimentos de estacionamentos e sobrelojas, sendo assim, este mapa pode subestimar o número de pavimentos em algumas unidades. Para o mapa de Albedo fez-se o mesmo procedimento, porém utilizou-se dos dados do campo da tabela relacionado à cobertura unidade, ou seja, de que material é constituído a cobertura do imóvel dentro de cada lote, ressaltando que se considera que o lote seja completamente coberto por aquele material sendo que na realidade isto nem sempre ocorre, por isto a área visualizada como cobertura poderá ser superestimada em alguns casos. Os tipos de cobertura podem ser classificados como: Fibrocimento, Telha Cerâmica, Telha metálica e laje e nos imóveis onde não se cadastrou esta informação foram rotulados como "Não se aplica", a partir desta classificação foi feita uma correlação com os valores do albedo de cada uma das matérias de acordo com os valores relacionados na quadro 1 , chegando a uma espacialização de uma estimativa do albedo de cada lote dentro da Região Central. Desta forma foi possível correlacionar à densidade construída, os valores de albedo, a arborização e as superfícies d'água com as temperaturas registradas em cada área. 
Quadro 1 - Relação do Albedo que constituem a cobertura das Edificações

\begin{tabular}{|c|c|c|c|c|c|c|}
\hline \multirow{2}{*}{\multicolumn{2}{|c|}{ Material }} & $\begin{array}{c}\text { Albedo } \\
\text { Envelhecido }\end{array}$ & $\begin{array}{c}\text { Emissividade } \\
\text { do material }\end{array}$ & $\begin{array}{c}\text { Temperatura } \\
\text { Superficial }\end{array}$ & $\begin{array}{c}\text { Temperatura } \\
\text { Superficial }\end{array}$ & \begin{tabular}{|c|} 
Diferença de \\
temperatura \\
entre o ar e \\
o material
\end{tabular} \\
\hline & & a envelhecido & e & Ts $(\mathrm{K})$ & Ts $\left({ }^{\circ} \mathrm{C}\right)$ & $(\mathrm{K})$ ou $\left({ }^{\circ} \mathrm{C}\right)$ \\
\hline \multicolumn{2}{|c|}{ Cerâmica Vermelha } & 0,53 & 0,9 & 309,92 & 36,8 & $-0,1$ \\
\hline \multicolumn{2}{|c|}{ Cerâmica Branca } & 0,54 & 0,9 & 309,37 & 36,2 & $-0,6$ \\
\hline \multicolumn{2}{|c|}{ Fibrocimento } & 0,34 & 0,9 & 320,26 & 47,1 & 10,3 \\
\hline \multirow{10}{*}{ Alumínio } & Sem pintura & 0,57 & 0,05 & 342,57 & 69,4 & 32,6 \\
\hline & Marfim & 0,47 & 0,9 & 313,23 & 40,1 & 3,2 \\
\hline & Amarelo & 0,45 & 0,9 & 314,32 & 41,2 & 4,3 \\
\hline & Bege & 0,45 & 0,9 & 314,32 & 41,2 & 4,3 \\
\hline & Azul Claro & 0,42 & 0,9 & 315,95 & 42,8 & 6,0 \\
\hline & Cinza Platina & 0,41 & 0,9 & 316,49 & 43,3 & 6,5 \\
\hline & Vermelho & 0,38 & 0,9 & 318,11 & 45,0 & 8,1 \\
\hline & Azul Santiago & 0,31 & 0,9 & 321,86 & 48,7 & 11,9 \\
\hline & Verde Imperial & 0,28 & 0,9 & 323,45 & 50,3 & 13,5 \\
\hline & Cerâmica Asteca & 0,26 & 0,9 & 324,50 & 51,4 & 14,5 \\
\hline \multirow{9}{*}{$\begin{array}{c}\text { Aço } \\
\text { Galvanizado }\end{array}$} & Sem pintura & 0,57 & 0,25 & 331,06 & 57,9 & 21,1 \\
\hline & Branco & 0,49 & 0,9 & 312,34 & 39,2 & 2,3 \\
\hline & Amarelo & 0,37 & 0,9 & 318,65 & 45,5 & 8,7 \\
\hline & Cinza Claro & 0,33 & 0,9 & 320,79 & 47,6 & 10,8 \\
\hline & Vermelho & 0,32 & 0,9 & 321,33 & 48,2 & 11,3 \\
\hline & Azul Escuro & 0,28 & 0,9 & 323,45 & 50,3 & 13,5 \\
\hline & Cinza Escuro & 0,27 & 0,9 & 323,98 & 50,8 & 14,0 \\
\hline & Verde & 0,21 & 0,9 & 327,13 & 54,0 & 17,1 \\
\hline & Cerâmica & 0,20 & 0,9 & 327,65 & 54,5 & 17,7 \\
\hline $\operatorname{Metal}(\mathrm{Al}+\mathrm{Z})$ & Sem pintura & 0,54 & 0,25 & 333,21 & 60,1 & 23,2 \\
\hline \multirow{8}{*}{$\begin{array}{l}\text { Cimento } \\
\text { colorido }\end{array}$} & Cinza escuro & 0,26 & 0,9 & 323,98 & 50,8 & 14,0 \\
\hline & $\begin{array}{c}\text { Cinza Escuro c/ } \\
\text { resina }\end{array}$ & 0,13 & 0,9 & 331,28 & 58,1 & 21,3 \\
\hline & Cinza claro & 0,49 & 0,9 & 322,92 & 49,8 & 12,9 \\
\hline & $\begin{array}{c}\text { Cinza Claro d } \\
\text { resina }\end{array}$ & 0,27 & 0,9 & 323,98 & 50,8 & 14,0 \\
\hline & Vermelha & 0,37 & 0,9 & 326,60 & 53,5 & 16,6 \\
\hline & $\begin{array}{l}\text { Vermelho cl } \\
\text { resina }\end{array}$ & 0,28 & 0,9 & 323,45 & 50,3 & 13,5 \\
\hline & Ocre & 0,33 & 0,9 & 323,98 & 50,8 & 14,0 \\
\hline & Ocre com resina & 0,23 & 0,9 & 326,08 & 52,9 & 16,1 \\
\hline \multirow{4}{*}{$\begin{array}{c}\text { Metal Termo- } \\
\text { acústico }\end{array}$} & Branca & 0,32 & 0,66 & 319,26 & 46,1 & 9,3 \\
\hline & Aluminio & 0,28 & 0,25 & 332,50 & 59,4 & 22,5 \\
\hline & Verde & 0,27 & 0,4 & 329,41 & 56,3 & 19,4 \\
\hline & Cerâmica & 0,43 & 0,66 & 323,39 & 50,2 & 13,4 \\
\hline
\end{tabular}

Fonte: Adaptado de Ferreira e Prado, 2003.

Finalmente, para elaboração dos mapas finais, Temperatura Manhã; Temperatura tarde; Sensação Térmica Manhã e Sensação Térmica Tarde, foi adicionado 0 shapefile dos pontos de controle no ambiente Arcmap, posteriormente foi adicionado quatro campos denominados temperatura manhã (Temp_1), temperatura tarde (Temp_2), sensação térmica manhã (TEv_1) e Sensação térmica tarde(TEv_2) na tabela de atributos deste shapefile, logo foram adicionados os valores das médias e dos índices anteriormente calculadas, de cada período do dia. Em seguida, foi realizada a interpolação dos dados, de cada um desses novos campos gerados através da ferramenta Geoestatistical Analyst por meio do método inverso do quadrado da distância, (IDW). O IDW é uma ferramenta de análise espacial a qual considera que cada amostra de ponto tem uma influência local que diminui com a distância. Este método admite que os pontos mais próximos para o processamento da célula influem mais fortemente que aqueles mais afastados.

Existem outros interpoladores como: Radial Basis Function (RBF), Kriging, Kernel, Polinomial Interpolation (LPI), dentre outros. A escolha do interpolador vai variar de acordo com o tipo de dado que se deseja representar, 
pois a partir das características do seu dado cada um desses pode ser melhor recomendado.

O RBF aplica uma série de técnicas exatas de interpolação, ou seja, a superfície passa através de cada valor de amostra medido, mas em comparação com IDW, o qual também é determinístico, ele pode assumir valores superiores aos dados registrados nos pontos de controle interpolados (Esri, s.d.).

Já a Krigagem é um método muito utilizado em trabalhos de climatologia, este interpolador trabalha na geração de uma superfície estimada a partir de um conjunto disperso de pontos com valores-z. Com relação ao Kernel atua com a intensidade de cada ponto determinado fenômeno em toda a região de estudo, com essa ferramenta é possível escolher trabalhar com ou sem barreiras absolutas, o que pode ser indicado para o caso de áreas com interferência do relevo, por exemplo. Por fim tem-se o LPI, o qual ajusta um polinômio a toda superfície, sendo cada um dentro de vizinhanças sobrepostas especificadas, essa vizinhança de pesquisa pode ser definida usando o tamanho e a forma, o número de vizinhos e a configuração do setor (Esri, s.d.).

Apesar do método IDW apresentar uma tendência de geração de círculos concêntricos no entorno do ponto amostral, os chamados "bull eyes", este se mostrou o método que melhor representou a área de estudo, visto que na aplicação das outras técnicas as respostas apresentadas não eram compatíveis a realidade microclimática conhecida da área de estudo. Destaca-se que por mais que existam recomendações para o uso de determinadas ferramentas, faz-se necessário investigar qual delas melhor representa com veracidade a área de estudo.

Feita a escolha do interpolador, os dados foram interpolados e criados rasters para cada campo interpolado, gerando os mapas separadamente.

Findada a elaboração dos mapas, foi possível executar a análise das zonas de conforto térmico, evidenciando a influência no tipo de uso e ocupação da terra e a resposta climática. Equacionar os ambientes favoráveis à ocupação humana, seja eles muito úmidos e quentes, quentes e secos ou frios e úmidos, relações entre a temperatura e umidade que resultam em um desconforto higrotérmico. E finalmente, através de todo o material elaborado, executar o detalhamento, mapeamento e conclusão das informações adquiridas.

\section{RESULTADOS E DISCUSSÃO}

Para compreensão da dinâmica climática da área de estudo foram analisadas as cartas sinóticas dos dias de coleta de dados em campo, neste sentido verificou-se as seguintes condições no dia 18 de Jun/13, estava atuando sobre a região uma alta pressão, caracterizando a atuação de um anticiclone, que propicia as condições de tempo estáveis, prevalecendo um céu sem a presença de nuvens, alta amplitude térmica diária, ventos calmos, umidade relativa do ar, no ápice térmico, por volta de $23^{\circ} \mathrm{C}$. No dia 19 de Jun/13 se mantém o centro de alta pressão, portanto, o dia mantém as mesmas condições atmosféricas do dia anterior, apresentando a máxima de $21,7^{\circ} \mathrm{C}$.

Já no dia 20 de Jun/13 visualiza-se um centro de baixa pressão próximo à região sudeste, que propiciou o céu encoberto ou parcialmente encoberto mais no final da tarde, além de ventos mais fortes, tendo a máxima temperatura 
registrada no dia de $24,3{ }^{\circ} \mathrm{C}$ e mínima de. No dia 21 de jun./13 a chegada da frente fria que já se aproximava, se estabelecendo no dia 21, marcando uma leve queda de temperatura, concebendo um centro de alta pressão, denotando dia de céu limpo, marcado pela temperatura máxima de 22,9.

No dia 30 de Jul./13 encontra-se um centro de alta pressão, com céu sem presença de nuvens, com atmosfera estável, a máxima registrada neste dia foi de $20,5^{\circ} \mathrm{C}$. Enfim no último dia de medição, dia 01 de Ago./13 um centro de baixa pressão, caracterizando uma atmosfera mais instável com ventos de maior velocidade, além de possibilidade de presença de nuvens durante alguns momentos do dia, a máxima registrada no dia foi de $26,1^{\circ} \mathrm{C}$.

A importância da sensação térmica relaciona-se não só à sensação de conforto das pessoas, como também ao seu desempenho no trabalho, saúde e qualidade de vida. A partir dos dados secundários e dos coletados em campo foi possível realizar um zoneamento da sensação térmica na região urbana do centro, junto deste zoneamento também foi realizado mapeamento de diferentes dados que irão subsidiar a análise e interpretação do zoneamento gerado.

Devido às diferentes características apresentadas nos pontos de controle durante todo o período de medição, a análise dos dados foi feita durante dois momentos do dia, manhã e tarde, os quais serão apresentados em um único mapa (Mapa de Temperatura Manhã e Tarde) de maneira a facilitar a comparação dos diferentes momentos.

O primeiro resultado a ser exposto é o zoneamento térmico da área de estudo, onde se constata durante o período da manhã, a formação de três zonas termais, que variam entre $14,8^{\circ} \mathrm{C}$ e $20^{\circ} \mathrm{C}$ dentro de uma amplitude térmica $5,2^{\circ} \mathrm{C}$, dentre as zonas formadas, destaca-se primeiramente os pontos de controle 5 e 7 que apresentam menores valores de temperatura, estes registros podem ser justificados pela proximidade dos pontos ao Rio Paraibuna, justificando as baixas temperaturas encontradas, este fato pode estar associado ao que Oke (1978) apontou como excesso de calor sensível pela diminuição do fluxo de calor latente. Quando analisado na perspectiva da presença de corpos hídricos detectamos um maior fluxo de calor latente e, portanto, diminuição do calor sensível, este fato poderá influenciar na temperatura do ambiente, gerando temperaturas do ar mais amenas.

Outra zona térmica verificada abrange as áreas próximas aos pontos 1,6 e uma grande região nas proximidades da calha Rio Paraibuna, nestes pontos os valores de temperatura variaram de $16,1^{\circ} \mathrm{C}$ a $19^{\circ} \mathrm{C}$. É evidente a ocorrência de uma zona mais fria circundando os limites da região urbana centro, este fato está atrelado a presença, de um curso d'água, poderia destacar a presença do corredor de ventos produzidos pela calha do rio Paraibuna, o que influencia na atenuação da temperatura outro fator é a vegetação que se encontra no ponto 1 , no qual se localiza o parque Halfeld, onde encontra-se a maior porção de área vegetada da região central, atuando no sombreamento da área atenuando neste sentido os valores de temperatura do ar.

O sombreamento da superfície pela vegetação favorece a manutenção do equilíbrio energético do ambiente, uma vez que acontece a interceptação da radiação solar direta, e posteriormente ocorre a reemissão do calor que promoveria o aquecimento do ar (OMETTO, 1981). Além da evapotranspiração 
da vegetação que contribui para a retirada da energia percebida, dessa forma, verifica-se resfriamento e a umidificação do ar, uma vez que se trata de um fenômeno endotérmico (MOTA, 1995 apud MODNA; VECCHIA, 2003).

Já em relação ao ponto 6 há de se destacar que o ponto apresenta maior altimetria diante de toda área de estudo, estando a 740 metros de altitude, ou seja a 65 metros de altitude mais elevado que a menor altitude encontrada dentro da área de estudo, nas proximidades das margens do rio Paraibuna com cerca de 675 metros de altitude como pode ser observado no mapa de Hipsometria (Figura 4)

No que tange os aspectos climáticos, enfatiza-se a estreita relação entre a situação topográfica e a formação de campos térmicos diferenciados. Mendonça (1994) ressalta que quanto maior for a movimentação e a variação altimétrica do relevo de um determinado sítio, maiores serão as variações de temperatura e umidade dentre outros elementos, no clima local e interurbano. Sendo a altitude, um dos mais conhecidos e importantes controladores climáticos. (ARMANI, 2009). Em contrapartida, o triângulo central que envolve as avenidas Rio Branco, Getulio Vargas e Itamar Franco possui uma intensa circulação de veículos e pessoas, o que favorece o aumento da temperatura na área.

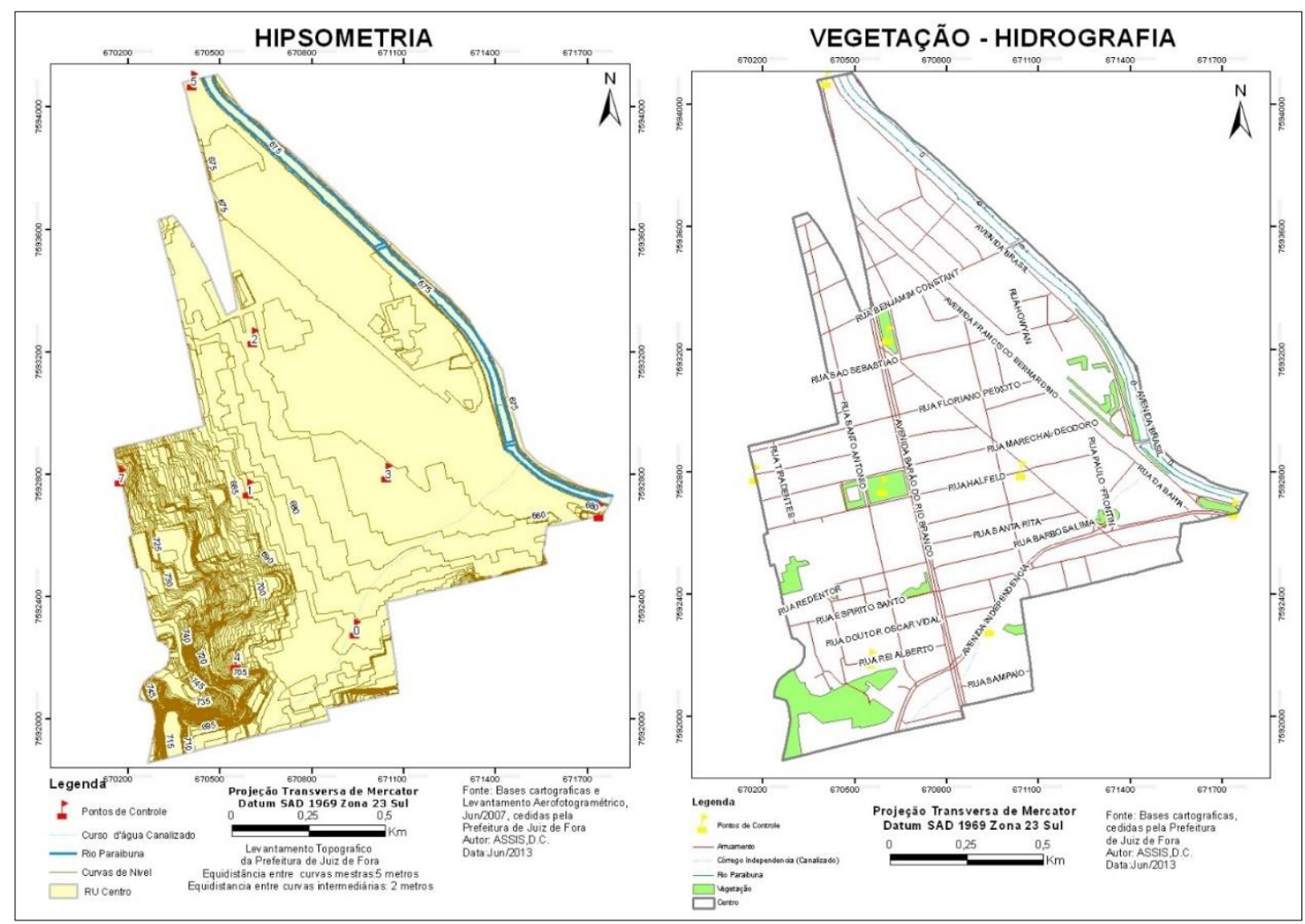

Figura 4 - Mapa de Hipsometria (a esquerda) e Mapa de Vegetação (a direita)

A diferenciação existente entre os valores de albedo dos materiais que constituem as coberturas de cada edificação também exercem função determinante na caracterização climática de uma determinada área, logo, ao observarmos na figura 5 , é possível aferir que a região urbana do centro 
constitui-se em sua maioria de materiais de baixíssimos valores de albedo, sendo que em algumas localidades esta ocorrência é ainda mais acentuada, caracterizando áreas de maior absorção de calor, e por consequência áreas mais quentes. Este fato pode ser observado ao redor do ponto de controle 3, em que as coberturas são predominantemente constituídas por laje revestida por cimento colorido cinza escuro, que possui albedo com valor de 0,26, considerado baixo albedo, consequentemente são áreas que apresentam grande absorção de calor. Podendo ser observado no mapa de temperatura Manhã e Tarde (Figura 6) que mostra que esta área possui maior temperatura em comparação com as demais.

Por fim, a zona mais quente do zoneamento matinal, no qual se verifica uma variação térmica de $19,1^{\circ} \mathrm{C}$ a $20^{\circ} \mathrm{C}$, ou seja, de $0,9^{\circ} \mathrm{C}$, que revela $\mathrm{o}$ triângulo central de condições térmicas diferenciadas, formado pelas vias: Rua Getúlio Vargas, Av. Itamar Franco e Av. Rio Branco como o mais quente, mesmo apresentando maior sombreamento na área onde se encontrava o equipamento, durante a maior parte da manhã, devido a alta presença de verticalizações. Foi a localidade que apresentou os dados de temperatura mais elevados, em comparação com os demais pontos de controle, justificado pela concentração de fluxos de veículos automotores, edificações e de pessoas, propiciando maior formação de calor antropogênico, sendo este associado ao calor sensível os principais responsáveis pela elevação da temperatura.

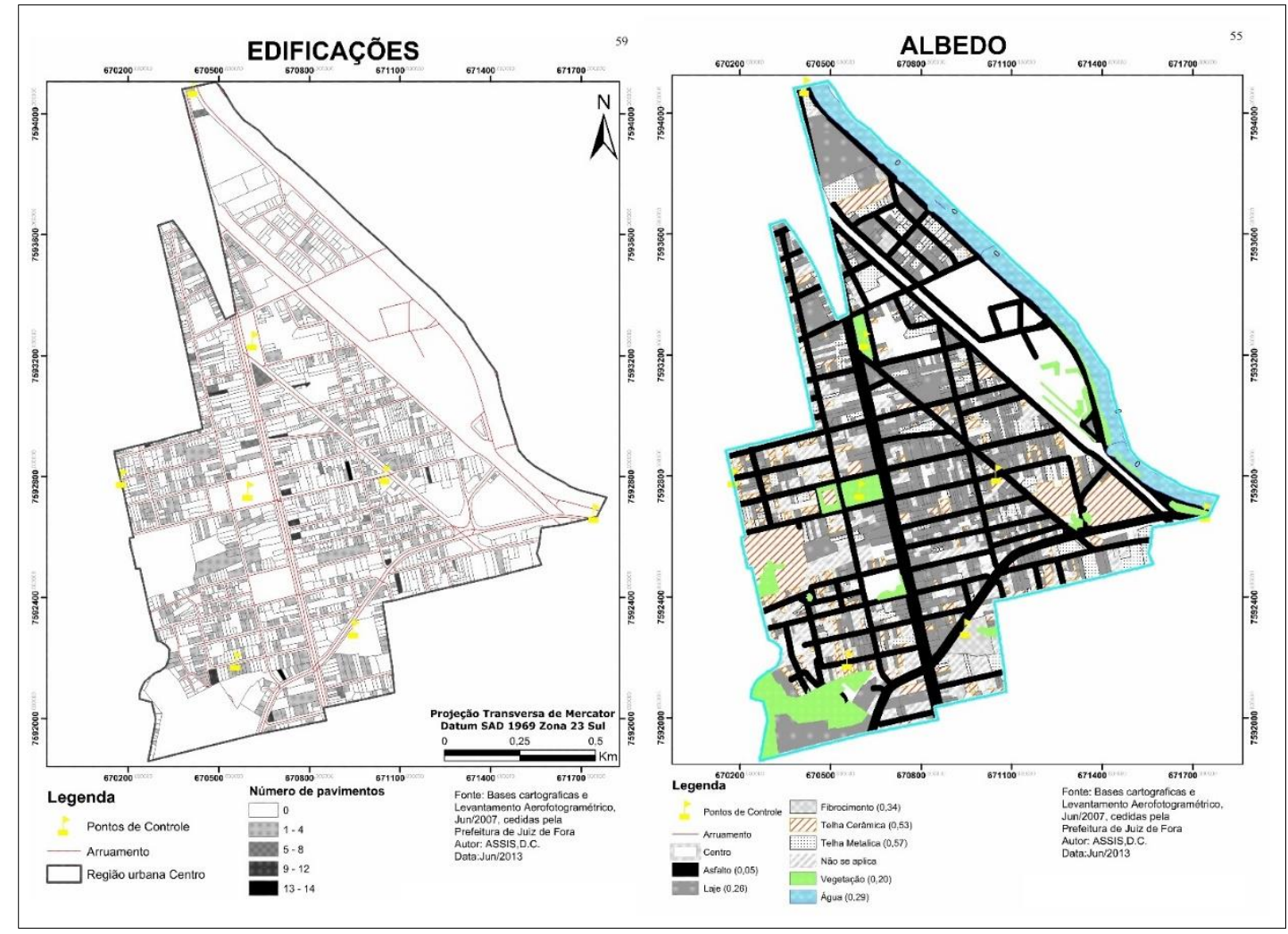

Figura 5 - Mapa Edificações (a esquerda) e Mapa de Albedo (a direita) 


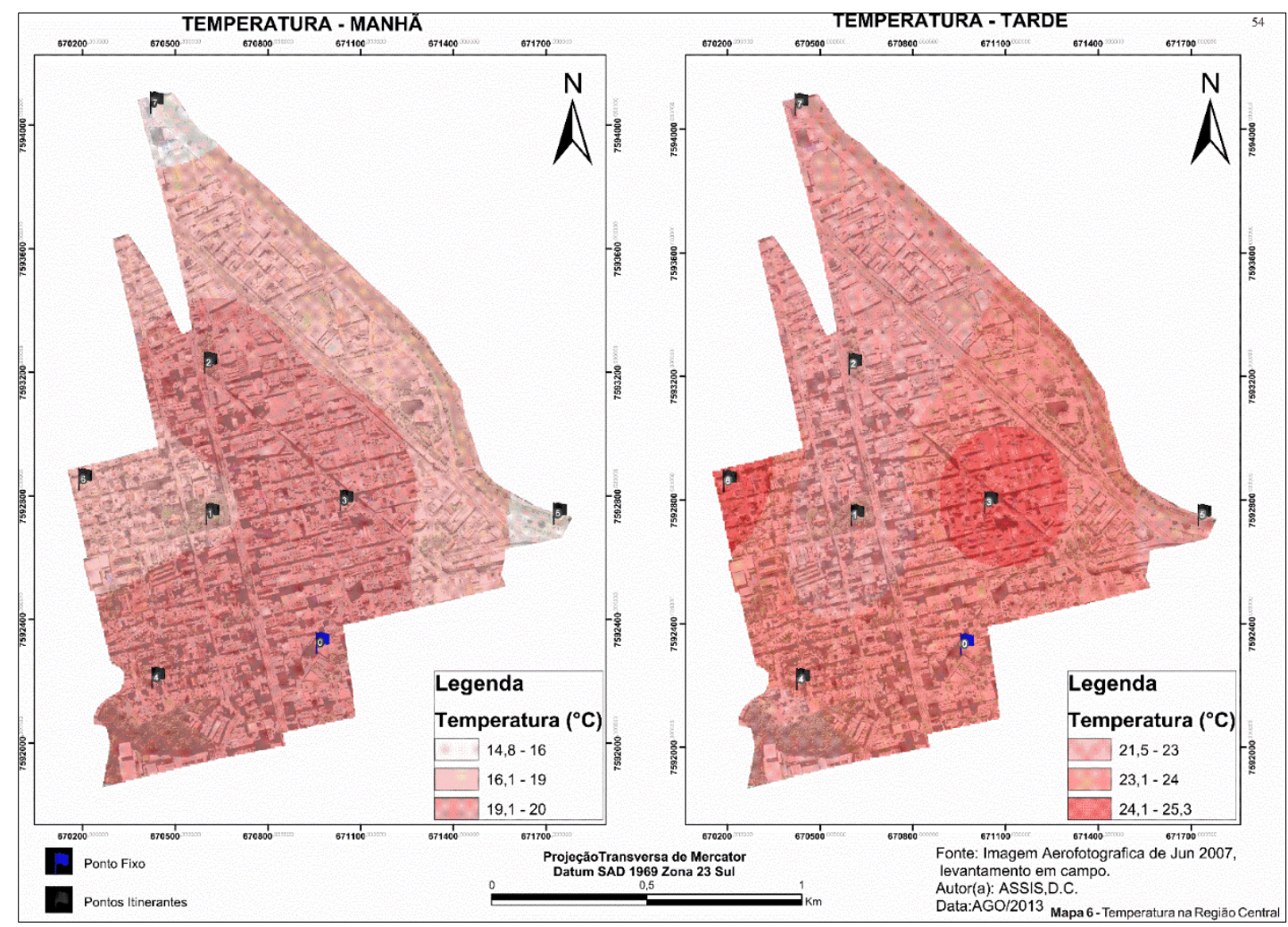

Figura 6 - Mapa de Temperatura na Região Urbana do Centro

O mapa do zoneamento térmico (Figura 6 ), foi também realizado para o período da tarde, no qual foi registrado uma amplitude térmica de $3,8^{\circ} \mathrm{C}$, que varia de $21,5^{\circ} \mathrm{C}$ a $25,3^{\circ} \mathrm{C}$, caracterizando um período do dia no qual registramos temperaturas mais elevadas. Podemos destacar variações em relação ao mapa de temperatura da manhã. Dentre elas, constatou-se que o ponto de controle 6 mostrou um comportamento diferenciado ao longo do dia, no qual foram registradas temperaturas mais elevadas no período da tarde, do que no período da manhã. Esse processo pode ser explicado pela orientação da incidência dos raios solares que tomam diferentes ângulos de incidência ao longo do dia. No caso deste ponto, o período da manhã foi marcado pelo sombreamento da estação meteorológica, devido as barreiras formadas pelas edificações. Já no período da tarde, ocorreu maior incidência dos raios solares, sendo assim apresentou maiores valores de temperatura. Esta justificativa também se aplica na área entorno ao ponto de controle 3, no qual ocorre também maior incidência de raios solares no período da tarde.

Outra área a se destacar é a região do extremo sudoeste da região centro próximo ao ponto de controle 4, na qual se encontra um pequeno fragmento de vegetação, oriundo de uma reserva particular. Nesta localidade, encontram-se temperaturas mais amenas, que podem ser explicadas pela presença da vegetação, já que toda vegetação presente nas ruas, nos quintais particulares, nas praças, em unidades de conservação e em áreas verdes, sejam de porte arbóreo ou herbáceo, podem contribuir, em intensidades diferenciadas, para a melhoria da ambiência urbana sobre diversos aspectos: amenizar a radiação solar na estação quente e modificar a temperatura e a umidade relativa do ar do recinto, através do sombreamento que reduz a carga térmica recebida 
pelos edifícios, veículos e pedestres; modifica a velocidade e direção dos ventos; interferir, quando em grande quantidade, na frequência das chuvas; através da fotossíntese e da respiração reduzindo a poluição do ar (MASCARÓ, 1990). A vegetação atua na atmosfera interurbana, funcionando como termorregulador, modificando o albedo das superfícies, já que interfere na radiação recebida durante o dia e perdida durante a noite (MASCARÓ, 1990). Além da presença da vegetação que pode ser observada no mapa de Vegetação e Hidrografia (Figura 4) ainda ocorre o sombreamento devido a incidência edifícios com muitos pavimentos, esta observação pode ser verificada através do Mapa Edificações (Figura 5).

O mapa de Edificações (Figura 5) resultou no processamento dos dados secundários cedidos pelo departamento de cadastro imobiliário da prefeitura do município. Através deste mapa, foi possível verificar o número de pavimentos de cada unidade de lote, e a questão de sombreamento das áreas, provocado pela verticalização na região em estudo, além da formação de possíveis corredores de vento, considerando que o vento estabelece estreita relação com a sensação térmica. A altura média das edificações interfere na ventilação urbana, pois edificações elevadas reduzem a velocidade do vento no nível do solo (GIVONI, 1997 APUD ROSSI, 2011). Desta maneira, as áreas entre as vias e as edificações são comprometidas pelo potencial de insolação e pela ventilação local, permitindo a canalização dos ventos ou bloqueio da ventilação.

Em relação aos corredores de vento é interessante ressaltar uma constatação visualizada em campo, na qual o ponto de controle 6 na av. Olegário Maciel destacou-se por um dado diferenciado dos demais pontos de medição. Neste ponto foi registrado a dominância de direção do vento no sentido Oeste, sendo registrados em apenas 3 momentos no sentido Noroeste. Neste sentido é possível conceber que na avenida em que o ponto se localiza, têm-se a predominância de imóveis com mais de um pavimento, o que caracteriza a formação de um corredor de vento.

É valido ressaltar que apesar de não ser o objetivo do presente trabalho, empiricamente visualizam-se outros pontos onde pode ocorrer a formação destes corredores, porém apenas no ponto de controle 6 , o dado foi constatado através dos registros do equipamento.

O zoneamento da sensação térmica/índice de temperatura efetiva da Região Central, no Mapa de Sensação térmica manhã (Figura 7) constatou-se um índice de temperatura efetiva que varia de menos de $13{ }^{\circ} \mathrm{C}$ a $18,4^{\circ} \mathrm{C}$, que representa as sensações térmicas de muito frio, frio e frio moderado, ou seja, evidencia que a área em estudo revela-se como ambiente de desconforto para população, já que para estes índices os corpos já apresentam respostas fisiológicas como extremo estresse ao frio e ligeiro resfriamento do corpo. 


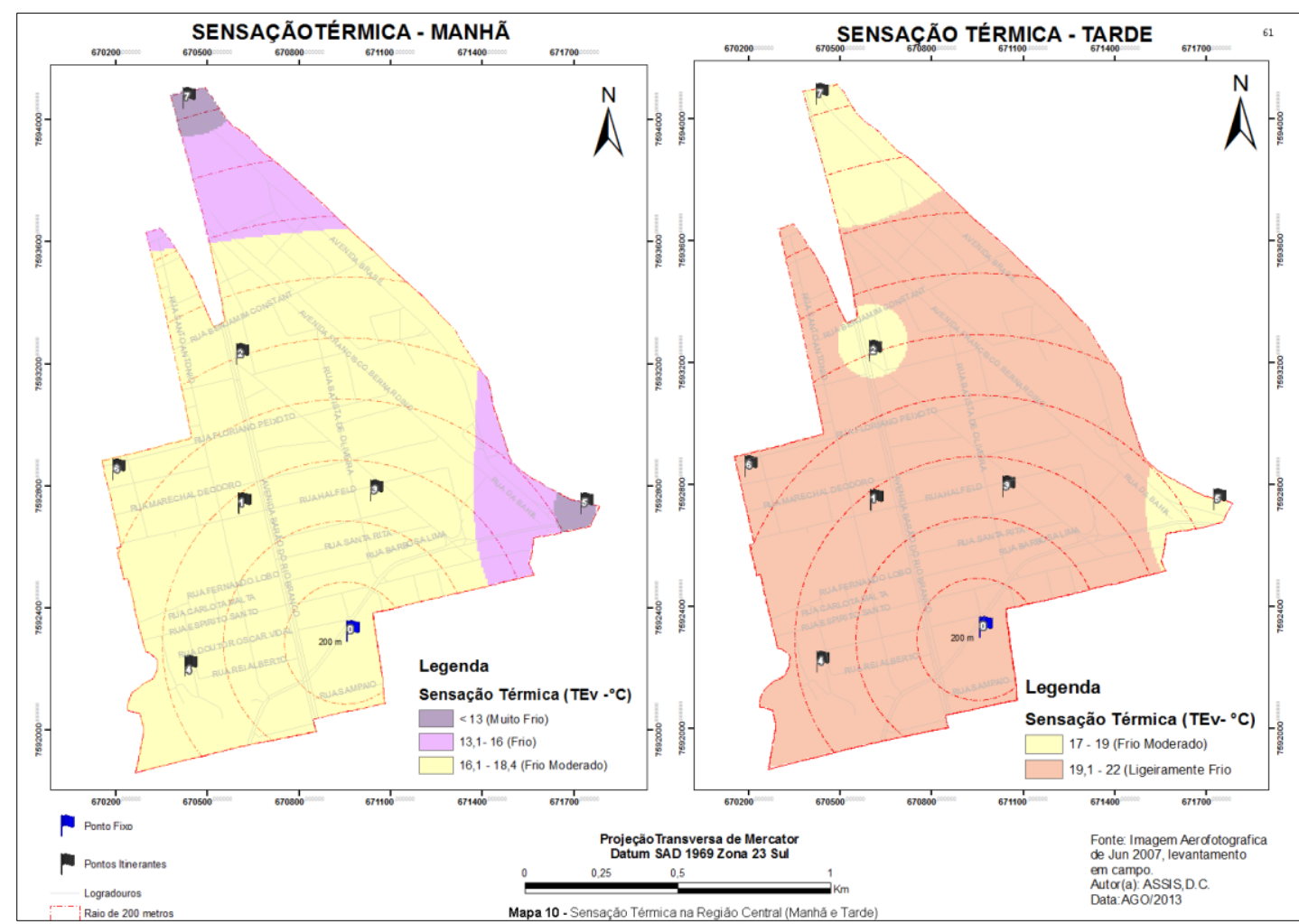

Figura 7 - Mapa Sensação Térmica na Região Urbana do Centro (Manhã e Tarde)

Neste sentido, os resultados desse primeiro momento de análise, destacam-se pelo caráter homogêneo das zonas de sensações térmicas diante da área em estudo. Duas zonas revelam valores mais baixos de temperatura, aquelas próximas aos pontos coletados nas proximidades do rio Paraibuna, demonstrando que em função da umidade presente e os elevados valores de velocidade do vento resultaram em ambientes ainda mais desconfortáveis a população humana. Visto isso, revela-se de suma importância políticas públicas que contemplem a manutenção da poda das árvores presentes em praças em estações mais frias do ano, permitindo uma incidência maior de radiação no ambiente, tornando-se mais confortáveis a população. E nos locais em que os ventos são muito intensos, a presença da vegetação também atenuaria sua velocidade, influenciando na temperatura efetiva, além do fator de edificações que interfere diretamente no sombreamento e formação de corredores de vento.

\section{CONSIDERAÇÕES FINAIS}

A partir dos resultados encontrados observa-se que durante o período do inverno, de maneira geral, a região central se apresenta como desconfortável à população devido aos baixos índices de temperatura efetiva (TEv) verificados. As áreas que sofrem com o sombreamento gerado pelas edificações apresentam maiores índices de desconforto, revelando diferentes situações durante o dia.

Outro fato a ser considerado foi a atuação das áreas verdes, as quais se mostram também como pontos de maior desconforto devido ao sombreamento gerado pelos exemplares arbóreos, o que reforça a importância da realização 
das podas da vegetação durante a estação de inverno. É importante ressaltar que esta constatação não vai de encontro à existência das áreas verdes, pois são reconhecidos todos os benefícios gerados pela mesma a população, principalmente no período do verão em que as áreas verdes atuam como possíveis ilhas de frescor dentro dos centros urbanos.

Os resultados do trabalho inicialmente se mostraram um tanto quanto inesperados, pelo fato de que inúmeros publicações relatarem centros urbanos como zonas desconfortáveis a população devido aos focos de calor, formando as chamadas ilhas de calor. No entanto destaco a importância do trabalho ter revelado resultados que fogem aos padrões, pois instiga a investigação dos fatores que os justificam, além de estimular diferentes reflexões no que toca o tema estudado

Espera-se que 0 presente trabalho tenha contribuído para 0 conhecimento da realidade térmica verificada na região urbana do centro, servido assim como subsídios para o planejamento e gestão da cidade, pelos órgãos governamentais e não governamentais. Para que desta forma a população tenha um ambiente mais confortável para se viver ou ao menos, menos desconfortável, proporcionando mais saúde e qualidade de vida.

\section{REFERÊNCIAS BIBLIOGRÁFICAS}

ARMANI, G. Análise topo e microclimática tridimensional em uma microbacia hidrográfica de clima tropical úmido de altitude. São Paulo, USP,2009.

ENVIRONMENTAL SYSTEMS RESEARCH INSTITUTE - ESRI. Informações de ferramentas embutidas no software ArcGis 10. s.d.

FANGER, P. O. Thermal Comfort. McGraw-Hill, New York, 1972.

FERREIRA, F.L.; PRADO, R.T.A. Medição do albedo e analise de sua influência na temperatura superficial dos materiais utilizados em cobertura de edifícios no Brasil. São Paulo: EDUSP, 2003.

GARCIA, F.F. Manual de climatologia aplicada: clima, médio ambiente y planificacíon. Madrid: Editorial síntesis S. A. 1985.

GOBO, J.P.A. Regionalização climática do Rio Grande do Sul com base no zoneamento do conforto térmico humano. Dissertação de Mestrado. Universidade de São Paulo, 2013.

IBGE. Censo Demográfico 2010.2 Disponível em: <http://www.censo2010.ibge.gov.br>.

INPE- CPTEC - Cartas Sinóticas - Disponível em: <http://www.cptec.inpe.br/>

LIMA, A. M. L. P. et al. Problemas de utilização na conceituação de termos como espaços livres, áreas verdes e correlatos. In: CONGRESSO BRASILEIRO DE ARBORIZAÇÃO URBANA, 2, 1994. São Luiz/MA. Anais... São Luiz: Imprensa EMATER/MA, 1994. p. 539-553.

MAIA, J. A.; GONÇALVES, F. L. T. Uma análise do conforto térmico e suas relações meteorotrópicas na cidade de São Paulo - Parte 1. XII Congresso Brasileiro de Meteorologia, Foz do Iguaçu, Paraná, 2002.

MASCARÓ, L.R. Luz, clima e arquitetura. 3a ed. São Paulo: Nobel, 1990. 
MENDONÇA, F.A. O Clima e o Planejamento Urbano de cidades de porte médio e pequena-proposição metodológica para estudo e sua aplicação à cidade de Londrina-PR. Tese de Doutorado em Geografia, USP, 300p. 1994.

MODNA, D. E; VECCHIA, F. Calor e áreas verdes: um estudo preliminar do clima de São Carlos, SP. ENCAC-COTEDI. Pág. 661-668. Curitiba, 2003.

MONTEIRO, C.A. Teoria e Clima Urbano. São Paulo: Instituto de Geografia, Faculdade de Filosofia, Letras e Ciências Humanas, Universidade de São Paulo, São Paulo, 1976. (Serie Teses e Monografias, n.25)

OMETTO, J. C. Bioclimatologia vegetal. Agronômica Ceres, 1981.

OKE, T. R. City size and the urban heat island. Atmospheric Environment, Oxford v.7, p.769-779, 1973.

OKE, T.R. Boundary Layer Climates. $2^{\mathrm{a}}$ ed. London: Ethuen \& CO,1978

OKE, T. R. Canyon Geometry and the nocturnal urban heat island: comparison of scale model and field observations. Journal of Climatology, New Jersey, v.1, p.237-254,1981.

OKE, T. R. et al. The energy balance of central Mexico City during the dry season. Atmospheric Environment, Oxford, v.33, p.3919-3930, 1999.

ROSSI, F. A.; KRÜGER, E.; NIKOLOPOULOU, M. A Influência da Configuração Urbana no Microclima e na Sensação Térmica em Ruas de Pedestre de Curitiba, Paraná. ENCONTRO NACIONAL SOBRE CONFORTO NO AMBIENTE CONSTRUÍDO, 2011.

SANTOS, M. A urbanização brasileira. São Paulo: Hucitec, 1994.

SOUZA, D. M.; NERY, J. T. O conforto térmico na perspectiva da Climatologia Geográfica. Geografia (Londrina), v. 21, n. 2, p. 65-83, 2013.

SUPING, Z. et al. Study of the relationships between weather conditions and the marathon race, and of meteorotropic effects on distance runners. International journal of biometeorology, v. 36, n. 2, p. 63-68, 1992

TASCA, L. As contradições e complementaridades nas leis urbanas de Juiz de Fora: dos planos aos projetos de intervenção. Tese de Doutorado. Rio de Janeiro. UFRJ, 2010.

TORRES, F.T. P. Relações entre fatores climáticos e ocorrências de incêndios florestais na cidade de Juiz de Fora (MG). Revista Caminhos de Geografia, Junho de 2006. 